\title{
Kıbrıs Adası Yapısal Süreksizliklerinin EGM08 Gravite Verileri Kullanılarak Belirlenmesi
}

\author{
Determination of Structural Discontinuities in Cyprus Island by Using EGM08 Gravity Data
}

Ali ELMAS

Karadeniz Teknik Üniversitesi, Mühendislik Fakültesi, Jeofizik Mühendisliği Bölümü, TRABZON

\section{$\ddot{O Z Z}$}

$\mathrm{Bu}$ çalışmada uydu gravite ve düşey birinci türev verilerine toplam yatay türev ve eğim açısı teknikleri uygulanarak, Kıbrıs Adası'nın yapısal süreksizliklerinin belirlenmesi amaçlanmıştır. Bölgenin yapısal süreksizlikleri belirlenirken, toplam yatay türev haritasının maksimum genlikleri ile eğim açısı haritasının sıfır genlik değerlerinden yararlanılmıştır. Belirlenen çizgisellikler, çalışma alanının bilinen süreksizlikleri ile karşılaştırılmıştır. Bu çalışma ile önceki çalışmalar arasında iyi bir uyum olmakla birlikte, yeni süreksizlik sınırları tespit edilmiştir. Bunun yanında Kıbrıs adasının temel kaya topoğrafyası, Parker-Oldenburg ters çözüm algoritması kullanılarak hesaplanmıştır. Çalışmanın, bölgenin jeolojik yapısının daha iyi anlaşılmasına katkı koyacağı düşünülmektedir.

Anahtar Kelimeler: Toplam Yatay Türev, Eğim Açısı, Kıbrıs Adası, Birinci Düşey Türev, Yapısal Süreksizlik.

\begin{abstract}
In this study, it was aimed to determine the structural discontinuities of the Cyprus Island by applying total horizontal derivative and tilt angle techniques to the vertical first derivative data of satellite gravity data. When determining the structural discontinuities of the zone, the maximum amplitudes of the total horizontal derivative map and the zero amplitude values of the tilt angle map were utilized. The specified lineaments are compared with known discontinuities in the study area. Along with a good harmony between this study and previous studies, new discontinuity boundaries were determined. In addition, the basement topography of the Cyprus Island is calculated by using the Parker-Oldenburg inversion algorithm. It is believed that the study will contribute to a better understanding of the geological structure of the region.
\end{abstract}

Keywords: Horizontal Gradient Magnitude, Tilt Angle, Cyprus Island, First Vertical Derivative, Structural Discontinuity. 
Elmas

\section{GíRiş}

Literatürde mevcut gravite çalışmalarında, fay türü yapıları ve çizgisellikleri belirlemek için Toplam Yatay Türev (TYT) ve Eğim Açısı (EA) teknikleri genellikle Bouguer gravite verilerine göre düzenlenmiştir (Nabighian, 1972; Miller ve Singh, 1994; Lyngsie vd., 2006; Cooper ve Cowan, 2006; Altınoğlu vd., 2015). Gravite verilerinin birinci düşey türev değerlerinin kullanımının faydalarını ilk kez Evjen (1936) belirtmiştir. Alçak geçişli süzgeç kullanılmasıyla elde edilen gravite verilerinin birinci düşey türev değerlerinin yorumlanmasında, fay türü jeolojik yapıları görüntülemek için EA tekniğinin ilk kullanımı Oruç ve Keskinsezer (2008), Oruç (2010) ve Oruç ve Selim (2011) tarafindan gerçekleştirilmiştir. Bu çalışmada ise yukarıda bahsedilen teknikler, rejyonal gravite verilerinin birinci düşey türev değerlerine uygulanmıştır. $\mathrm{Bu}$ sebeple, öncelikle bölgeye ait Bouguer gravite verilerinden rejyonal ve yerel gravite verilerini elde etmek için Butterworth alçak geçişli süzgeç kullanılmıştır. Daha sonra, rejyonal gravite verilerinin birinci düşey türev değerlerini hesaplamak için Hızlı Fourier dönüşümü (FFT) yöntemi (Gunn, 1975) kullanılmıştır. Çalışma alanındaki yeni fay türü yapıları ve çizgisellikleri belirlemek için de Arısoy ve Dikmen (2011) tarafından geliştirilen, TYT ve EA sınır analiz tekniklerini de içeren POTENSOFT programı kullanılmıştır. Parker-Oldenburg algoritması, temel kaya geometrisini görüntülemek için son zamanlarda yaygın olarak kullanılmaktadır (Oruç vd., 2013). Gomez-Ortiz ve Agarwal (2005) bu algoritmayı Matlab programlama diliyle yazarak yayımlamışlardır.

Ergon (1986), Kibris'in manyetik haritalarını veri-işlem yöntemleriyle analiz edilerek bölgenin genel yapıs1 ve bilinen cevher yataklarıla olan ilişkilerini ele almıştır. Literatürde birçok araştırmacı Kıbrıs'ın Bouguer gravite anomalisini değişik yöntemlerle yorumlayarak, alana ait temel jeolojik birimleri belirlemeye çalışmışlardır (Moores ve Vine, 1971; Greenbaum, 1972; Bear, 1963; Gass ve MassonSmith, 1963; Robertson, 1975; Robertson ve Woodcock, 1979). Vine ve Moores (1989) yaptıkları paleomanyetik çalışmalarla Trodos Masifi'nin yapısının, okyanusal tabakalarla ilişkisini ortaya koymuşlardır. Khan vd. (1972) bu masifin $0.5 \mathrm{~km}$ kalınlığındaki yüzey tabakası altında iki kırılma yüzeyi saptamıș ve ikinci katmanın kalınlığının $1.5 \mathrm{~km}$ ile $2.0 \mathrm{~km}$ arasında değiştiğini bulmuşlardır.

$\mathrm{Bu}$ çalışmada Kıbrıs Adasıı'nın rejyonal gravite verilerine birinci düşey türev yöntemi, sınır analiz ve ters çözüm teknikleri uygulanarak, Kıbrıs Adası'nın tektonik yapısı ile temel kaya topoğrafyası modellenmeye çalışılacaktır.

\section{KIBRIS ADASI GENEL JEOLOJISİ}

Kıbrıs'ta ilk jeolojik çalışma Gaudry (1862) tarafından yapılmıştır. Kıbrıs Adası; Beşparmak Dağları, Trodos Ofiyoliti (Trodos Masifi) ve Mamonia Kompleksi olmak üzere üç tektonik birimi kapsar (Şekil 1). Bunların her biri Doğu Akdeniz'de Neotetis okyanus havzalarının kapanmasıyla sonuçlanan levha hareketlerinin ve çok çeşitli paleo-ortamların ürünleridir (Hakyemez, 2004).

Geç Triyas riftleşmesi ile Gondwana'nın kuzey kenarından ayrılan Kimmer Kitası Erken Jura' da parçalanarak mikrokıtaları oluşturmuştur (Şengör ve Yılmaz, 1981). Beşparmaklar bölgesi, bu mikrokıtalardan biri olup yavaşça çökmekte olan bir karbonat platformunu temsil eden Anatolid-Torid platformunun güney kenarında yer almıştır (Robertson ve Woodcock, 1986). Geç Kretase'de güneydeki okyanus havzası içinde 
Afrika-Avrasya yaklaşmasına bağlı olarak, kuzey yönlü bir dalma-batma zonu üzerinde Trodos Ofiyoliti oluşmuştur. Bölgesel ölçekte Trodos Ofiyoliti Mesozoyik'te Doğu Akdeniz'de yer alan çok sayıda, küçük okyanus havzalarından birinin bir bölümünü içerir (Robertson ve Xenophontos, 1993) ve Kıbrıs'tan başlayarak doğuya doğru Türkiye ve İran'dan geçerek Umman'a kadar uzanan bir kuşakta yüzeyler. Bu ofiyolit kuşağı Arap-Afrika levhasının kuzey kenarını oluşturan Alpin dağ zincirinin önemli bir bölümüdür. Güneybatı Kıbrıs'taki Mamonia Kompleksi başlıca Triyas lavları ve Mesozoyik sedimanter kayaçları ile daha az oranda ofiyolitik kayaçlar, ekstrüzifler ve fay zonları boyunca yer alan metamorfiklerden oluşmaktadır (Robertson ve Xenophontos, 1993). Mesozoyik platform kayaçları yaygın şekilde makaslanmış, tektonik olarak breşleşmiş ve düşeye yakın eğimli fay zonları boyunca dilimlenerek yukarı çıkarılmıştır (Robertson ve Woodcock, 1986). Afrika ve Avrasya'nın devam eden yaklaşması Güney Kıbrıs açıklarında yer alan hendekteki dalmabatma ile karşılanmış ve hem Trodos hem de Beşparmak Dağları Oligosen-Miyosen dönemleri boyunca genel olarak bir yay önü konumda kalmıştır. Bölge hızla çökmüş ve kuzeydoğu'dan (Adana Havzası veya İskenderun Körfezi) beslenen dev bir denizaltı yelpazesi kompleksinin derine gömülmüş bir parçasını oluşturmuş ve kalın bir çökel istifiyle örtülmüştür (Weiler, 1965). Miyosen sonundan orta Pliyosen'e kadar yenilenen sıkışma deformasyonu sonucunda Beşparmak Dağları'nın doğu ve merkezi bölgelerinde büyük ölçekli bindirme ve kuzey eğimlenme gerçekleşmiştir (Robertson ve Woodcock, 1986). Beşparmak Dağları'nın geç Miyosen dönemindeki son yerleşimi Mesarya Ovası'nın altında Trodos volkanik temelinin faylanmasına neden olmuş, bu faylar boyunca daha sonra gerçekleşen hareketler Mesarya bölgesi Pliyosen sedimantasyonunu etkilemiştir (Robertson, 1977). Trodos Masifi çevresi ve Güneybatı Kıbrıs Mamonia Napları'nın yerleşimi sonrasında kuzeydeki Beşparmaklar bölgesinden farklı bir jeolojik gelişim göstermiştir: Trodos Masifi çevresi Kampaniyen'de Perapedhi Formasyonu'nun umber ve radyolaritleri, Maastrihtiyen-Tersiyer döneminde de Lefkara Grubu'nun tebeşirleriyle temsil edilen pelajik bir çökelime sahne olurken adanın güneybatı bölgesi Maastrihtiyen'in bir bölümünde normal pelajik çökelimden uzaktır. Çünkü o dönemde oldukça kalın bir volkanojenik çökel istifi depolanmış ve Trodos Masifi'nin güney kenarı, allokton birimlerin bu çökellerin üstüne yerleşmesiyle şiddetli olarak deforme olmuştur (Robertson ve Hudson, 1974). Bu dönemde Trodos Masifi'nin bütün güney kenarı dilimlenmiş, bütün bir kütle olarak güneybatıya doğru eğimlenmiş ve bu dönemin hemen sonrasinda birikmeye başlayacak olan marn ve tebeşirlerin pelajik karakteriyle belirlenen derin bir su kütlesi altında kalmıştır. Bu kenar boyunca Paleosen ve erkenorta Eosen döneminde pelajik karbonat çökelimi devam etmiştir. Trodos kuzeyi ise yükselmiş, çok düşük sedimantasyon etkisi altında kalmış veya olasılıkla denizaltı erozyonuna uğramıştır. Bu bölgelerde Orta ve Üst Eosen çökelleri çok incedir veya hiç yoktur. Trodos'un güney ve doğusunda pelajik tebeşir ve marnlar Oligosenerken Miyosen sirasında da maksimum kalınlıkta çökelirken kuzeyde zaten yükselmiş olan bölgelerde bu çökeller yine çok incedir. Trodos'un kuzeybatısında bu dönem çökelleri bölgesel yükselimin önemli kanıtı olan resif ve kavkılı kireçtaşı oluşumlarını içermektedir (Robertson, 1977). Orta Miyosen başlangıcında Lefkara sedimantasyonunu sona erdiren tektonik hareketler Trodos Masifi'nin bugünkü güney kenarına yakın bir bölge olan Limasol Ormanı bölgesinin yükselimiyle başlamıştır. Üste doğru 
Elmas

sığlaşarak lagün çökelleriyle devam eden karbonat istifi, yerel resif gelişimleri ve jips depolanması ile sona ermiştir. Trodos Masifi’nin büyük bölümü Pliyosen dönemi boyunca tektonik olarak duraylı, su üstü konumda veya düşük su düzeyi altında kalmıştır (Robertson, 1977). Pleyistosen'de tektonik duraylilık sonrası birbirini izleyen şiddetli ve aralıklı yükselim dönemleri başlamıştır (Robertson, 1977). Kıbrıs'ın yükselimini, köken olarak Afrika kıtasına ait bir birim olarak düşünülen Eratosthenes denizaltı tepesinin Kıbris aktif kenarıyla güçlü çarpışması sağlamaktadır (Robertson vd., 1995). Doğu Akdeniz'in doğusunda deprem verileri kuzeydoğu yönlü dalma-batmanın yerel olarak Güneybatı Kıbrıs altında devam ettiğini göstermektedir (Kempler ve Ben Avraham, 1987; Ambraseys ve Adams, 1993).

Çalışma alanının jeolojisi ve bölgedeki önemli yapısal elemanlar Şekil 1'de görülmektedir. Farklı araştırmacılar değişik zamanlarda (Gaudry, 1862; Baroz, 1979; McCallum ve Robertson, 1995a, 1995b; Çuhadar vd., 1997; Hakyemezvd., 2002; Hakyemez, 2004) farklı veri setleri kullanarak, Kıbrıs'ın tektonik yapısını araştırmışlardır. Bu çalışmada ise Kıbrıs Adası'na ait rejyonal gravite verilerinin birinci düşey türev değerleri kullanılarak, bölgeye ait fay türü jeolojik yapılar ve çizgisellikler gibi süreksizlik gösteren yapı sınırları belirlenmeye çalış1lmıştır.

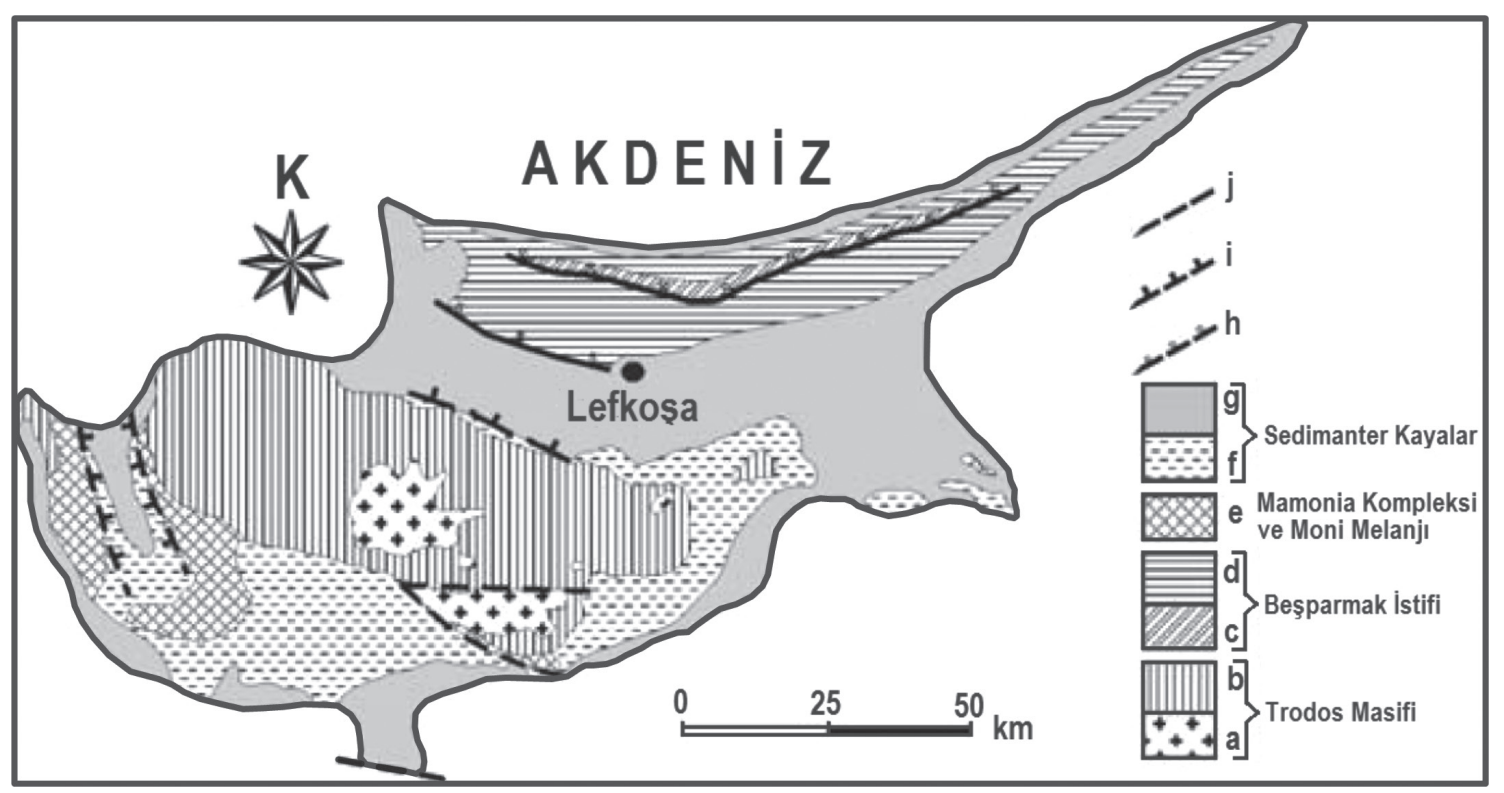

Şekil 1. Kıbrıs Adası'nın yapısal birimleri. a: plütonik kompleks, b: ekstrüzifler ve levha dayklar, c: MesozoyikEosen, d: Oligosen-Miyosen, e: Mamonia kompleksi ve Moni melanjı, f: Kretase- Miyosen, g: Pliyosen-güncel, h: bindirme, i: normal fay, j: tektonik hat (Hakyemez 2004'den düzenlenmiştir).

Figure 1. Structural units of Cyprus island. a: plutonic complex, b: extruders and plate dykes, c: Mesozoic-Eocene, $d$ : Oligocene-Miocene, e: Mamonia complex and Moni-melange, f: Cretaceous-Miocene, g: Pliocene-current, $h$ : overlap, i: normal fault, $j$ : tectonic line (modified after Hakyemez, 2004). 


\section{KIBRIS ADASI EGM08 BOUGUER ANOMALILERİ}

EGM08 Bouguer gravite verileri, CGMW (Commission for the Geological Map of the World) ve UNESCO işbirliği ile 2008 yılı başlarında oluşturulan WGM (World Gravity Map) projesinin bir sonucudur (Sönmez, 2015). WGM projesi UNESCO'nun desteği altındaki Uluslararası Jeodezi Birliği’ne (IAG) bağlı Uluslararası Gravite Alanı Servisi'nin (IGFS) bir merkezi olan Bureau Gravimetrique International (BGI) tarafindan yürütülmüştür. Projede öncelikle Serbest Hava ve Bouguer gravite verileri kara, hava ve deniz ölçümleri ve son yıllarda yapılan küresel ve bölgesel ölçümlerin arşiv bilgileri derlenmiştir. Daha sonra 5'x5' aralıklarda (yaklaşık $9 \mathrm{~km}$ ) yerkürenin topografya ve batimetri veri tabanından da yararlanılarak ultra yüksek dereceli küresel harmoniklerle Bouguer anomali grid verileri 1 mGal duyarlılığında belirlenerek yayınlanmıştır (Pavlis vd., 2008). EGM08 uydu ve yüzey ölçümlerini birleştiren küresel bir modeldir. Şekil 2'de görülen çalışma alanına ait Bouguer gravite verileri Dünya Gravite Modeli'nden (EGM08) elde edilmiştir (Pavlis vd., 2008).

Tektonik yapılarla ilgili olarak maksimum gravite değerleri Trodos Masifi üzerinde görülmektedir (Şekil 2). Tektonik yapılarla ilişkili olarak, gravite değerleri farklı doğrultularda yönelimler sergilemektedir (Şekil 2).

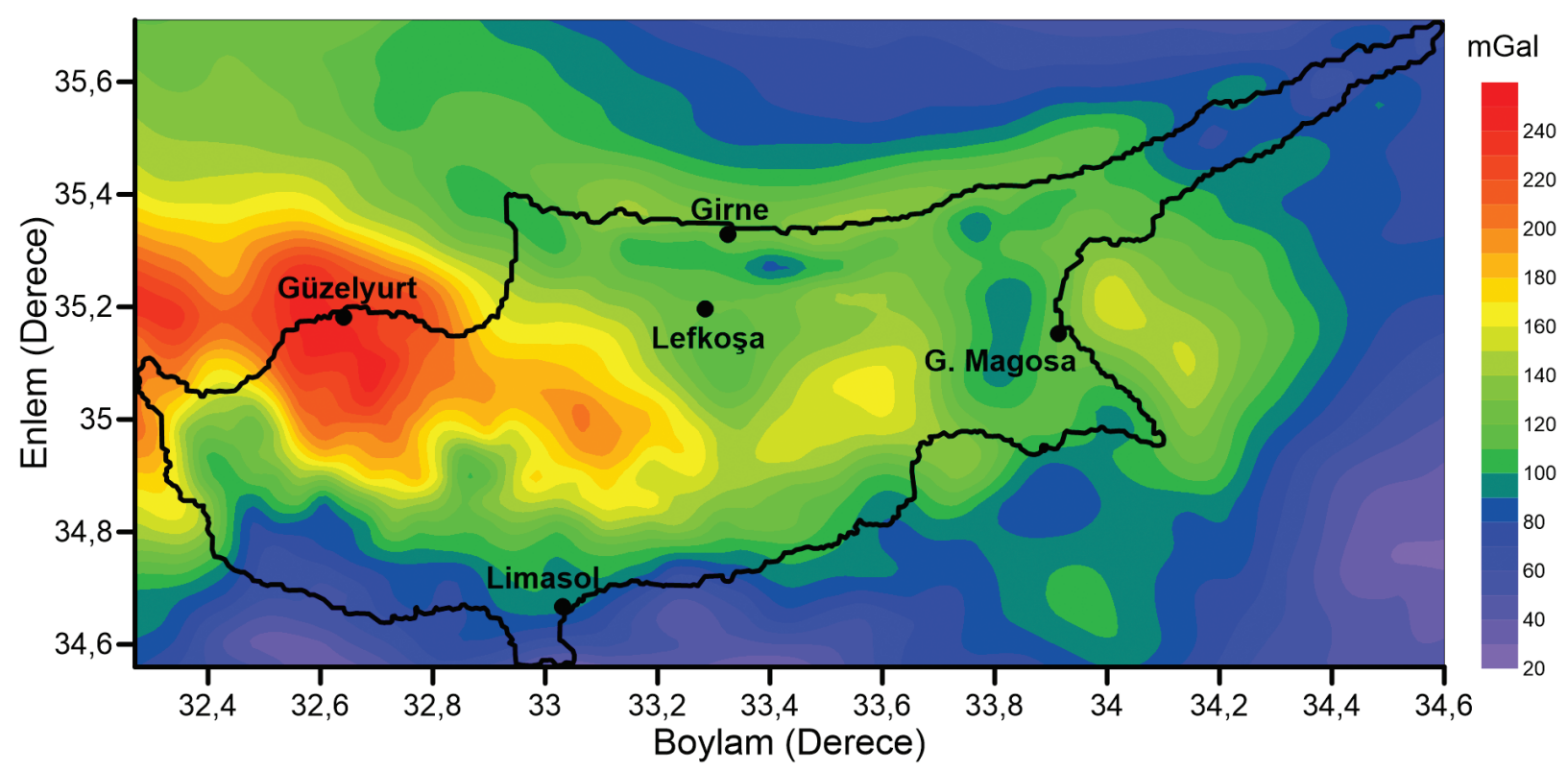

Şekil 2. Kıbrıs ve civarının EGM08 Bouguer anomali haritası.

Figure 2. EGM08 Bouguer anomaly map of Cyprus and its surroundings. 
Elmas

Çalışma alanına ait derin ara yüzey sinırlarının ortalama derinlikleri, Bhattacharyya (1967) tarafindan geliştirilen radyal ortalamalı genlik spektrumu tekniği kullanılarak belirlenmiştir. $\mathrm{Bu}$ teknik, gravite verilerinin 2B Fourier dönüşümüne bağlıdır. Ara yüzey derinlikleri, dalga sayısı ile gravite verilerinin logaritmik güç spektrumu arasındaki doğrusal ilişkinin eğiminden elde edilir. Hesaplama sonucunda üç farklı ara yüzey derinliği bulunmuştur (Şekil 3). Genlik spektrumunun eğimli parçalarından sediment, temel kaya ve Moho sinırlarına ait derinlikler sirasıyla $2.27 \mathrm{~km}$, $5.89 \mathrm{~km}$ ve $25.78 \mathrm{~km}$ olarak bulunmuştur (Şekil $3)$.

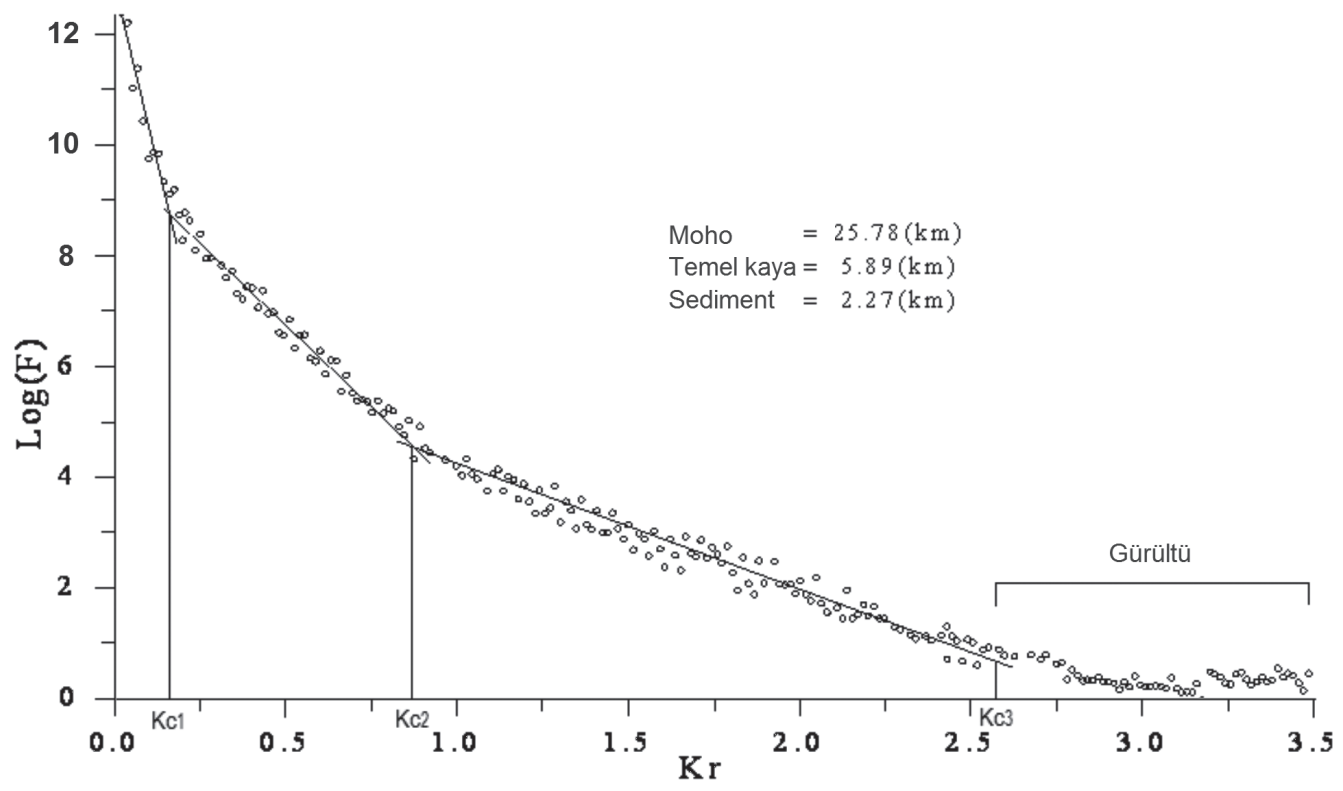

Şekil 3. Kıbrıs adası EGM08 Bouguer anomalilerinin radyal ortalamalı logaritmik genlik spektrumu ve derin ara yüzey sınırlarının ortalama derinliklerinin ve kritik dalga sayılarının belirlenmesi.

Figure 3. Radial average logarithmic amplitude spectrum of Cyprus island EGM08 Bouguer anomalies and determination of mean depths and critical wave numbers of deep interface boundaries.

Genlik spektrumu tekniği kullanılarak $5.89 \mathrm{~km}$ derinlik değeri hesaplanan temel kaya topoğrafyasını modellemek için ParkerOldenburg algoritması kullanılmıştır. $\mathrm{Bu}$ algoritma, ara yüzeyin Fourier dönüşümü ile gravite verilerinin Fourier dönüşümü arasındaki bağıntıya dayanır. Bu bağıntı, jeolojik yapının bir ara yüzeyinin yoğunluğundan ve belirlenen derinliğinden yinelenerek oluşturulur (Parker, 1973; Oldenburg, 1974). Düzensiz bir homojen tabakanın gravite değerlerini hesaplamak için kullanılan Fourier dönüşümü aşağıdaki gibidir:

$$
f\left[z_{1}(x)\right]=-\frac{f[\Delta g(x)] e^{|k| z_{0}}}{2 \pi G \rho}-\sum_{n=2}^{\infty} \frac{|k|^{n-1}}{n !} f\left[z_{1}^{n}(x)\right]
$$


Burada $f[\Delta g(x)], z_{0}, z_{1}(x), k, G$, ve $\rho$ parametreleri, jeolojik yapının ara yüzeyinin sırasıyla gravite değerlerinin Fourier dönüşümü, ortalama derinliği, her ölçü noktası altındaki derinlik, dalga sayısı, gravite sabiti ve sinırının üstündeki ve altındaki ortamların yoğunluklarından belirlenen yoğunluk farkıdır. Ortalama $\mathrm{z}_{0}$ derinliğinden ve yoğunluk farkından hareketle ara yüzey sınır derinlikleri denklem 1 'den yinelemeli olarak hesaplanır. Yinelemeler belli bir yineleme sayısına ulaşıncaya veya sıfıra bir önceki ve sonraki yinelemede kestirilen derinlikler arasındaki hataların, sıfıra yakın seçilen yakınsama kriterinden küçük oluncaya kadar devam ettirilir.

\section{SÜREKSIZLIKLERİ BELIRLEME TEKNIKLERI}

Özellikle potansiyel alan verileri ile sığ veya derin faylar arasındaki ilişkiyi görüntüleyebilmek için kullanışlı olan TYT tekniği, jeolojik yapıların yanal süreksizlik sınırlarını belirleyebilmek için kullanılmaktadır (Lyngsie vd., 2006). TYT'nin genliği, birinci düşey türev değerlerine göre denklem 2'de verildiği gibi ifade edilir:

$$
\mathrm{TYT}=\sqrt{\left(\frac{\partial^{2} \mathrm{~g}}{\partial \mathrm{x} \partial \mathrm{z}}\right)^{2}+\left(\frac{\partial^{2} \mathrm{~g}}{\partial \mathrm{y} \partial \mathrm{z}}\right)^{2}}
$$

Burada $\frac{\partial^{2} \mathrm{~g}}{\partial \mathrm{x} \partial \mathrm{z}}$ ve $\frac{\partial^{2} \mathrm{~g}}{\partial \mathrm{y} \partial \mathrm{z}}$ ve terimleri rejyonal gravite verilerinin birinci düşey türev değerlerinin $\mathrm{x}$ - ve $\mathrm{y}$ - yönlerindeki türevlerini ifade etmektedir. TYT tekniğinin en çok tartışılan zayıf yönü, derin veya düşük yoğunluk sunan yeraltı yapılarına ait kenarlarda düşük genlik sunmaları ve böylece bu yapılara ait kenar etkilerini yeterince yansitamamalarıdır (Miller ve Singh, 1994; Cooper ve Cowan, 2006). Yöntemin bu zayıf noktasindan yola çıkan araştırmacılar son yıllarda normalize edilmiş türev yöntemleri geliştirmişlerdir (Miller ve Singh, 1994; Cooper ve Cowan, 2006). Bu tekniklerden biri EA tekniğidir ve hem sığ, hem de derin yapılar için iyi sonuçlar vermektedir (Miller ve Singh, 1994). EA tekniği, yoğunluk farkının güçlü veya zayıf olması durumunda iyi sonuç verir. Eğer yoğunluk farkı pozitifse, EA değerinin işareti anomaliye sebep olan kaynağın üzerinde pozitif, kenarlarında sıfır ve dişında negatif olur. Denklem 3'e göre, düşey türevin toplam yatay türeve oranının ark tanjantı, EA haritasında sıfır değerler üretir. Bu sıfır değerli konturlar jeolojik birimlerin ve fay tipi yapıların, yoğunluk değişimlerine bağlı olarak yanal süreksizlik sınırlarını temsil etmektedir (Miller ve Singh, 1994).

$$
\varphi=\tan ^{-1}\left(\frac{\frac{\partial^{2} \mathrm{~g}}{\partial \mathrm{z}^{2}}}{\sqrt{\left(\frac{\partial^{2} \mathrm{~g}}{\partial \mathrm{x} \partial \mathrm{z}}\right)^{2}+\left(\frac{\partial^{2} \mathrm{~g}}{\partial \mathrm{y} \partial \mathrm{z}}\right)^{2}}}\right)
$$

Burada $\varphi$ parametresi EA'nın genliğini temsil eder.

Şekil 4a ve 4b'de, yoğunluk farkları aynı $\left(0.3 \mathrm{gr} / \mathrm{cm}^{3}\right)$ olan farklı derinlik ve boyutlara sahip yedi dikdörtgen cisimden oluşan kuramsal model görülmektedir. Kuramsal modelin etkilerini, çizgisel yapıları belirlemede kullanılan teknikler üzerinde görmek için, Arısoy ve Dikmen (2011) tarafından geliştirilen POTENSOFT yazılımı kullanılmıştır. Cisimler aynı yoğunluk farkına sahip olmalarına rağmen, yüzeyden olan derinlikleri sirasiyla 1, 2, 3, 4, 5, 6 ve $7 \mathrm{~km}$ olarak tasarlanmıştır (Şekil 4b). Bu modelden hesaplanan gravite haritası Şekil 4c'de görülmektedir. Hesaplanan gravite verilerinin birinci düşey türev haritası ise Şekil $4 d$ 'de görülmektedir. Şekil 4c ve 4d karşılaştırıldığında, 


\section{Elmas}

farklı derinliklerdeki cisimlerin konumlarını görüntüleme işleminde, türev haritasının gravite haritasına göre daha başarılı sonuç verdiği görülmektedir. Daha sonra, TYT ve EA teknikleri, kuramsal modelden hesaplanan gravite değerleri ile ve gravite değerlerinin birinci düşey türev değerleri ile test edilmiştir.

Şekil 5a ve 5b'deki TYT tekniğinin sonuçlarına göre, sığ cisimlerin yanal süreksizlik sınırları iyi bir biçimde görüntülenebiliyorken, cismin derinliği arttıkça bu netliğin azaldığ1 görülmektedir. Ayrıca burada, türev verileri kullanılarak bulunan sonucun (Şekil 5b) gravite verileri kullanılarak bulunan sonuçtan (Şekil 5a) daha doğru olduğu görülmektedir. TYT tekniğinin doğasından dolayı, cismin derinliği arttıkça maksimum genlikte hızlı bir azalma olur. Böylece bu tekniğin sığ süreksizliklere daha duyarlı olduğu anlaşılmaktadır. EA tekniği kullanılarak bulunan genlik haritaları ise Şekil $5 \mathrm{c}$ ve $5 \mathrm{~d}$ 'de görülmektedir. $\mathrm{Bu}$ tekniğin genlik haritalarına bakıldığında, cisimlerin sınırları üzerinde sıfır genlik değerleri görülür. Ancak, türev verileri kullanılarak bulunan EA genlik haritasına bakıldığında, sıfır konturlarının, derinlik artsa da, süreksizlik sinırları üzerinde olduğu görülmektedir (Şekil 5d). Diğer taraftan, doğrudan gravite verileri kullanılarak bulunan EA genlik haritasına bakıldığında ise, sıfır konturlarının, özellikle derinlik arttıkça, süreksizlik sınırlarından uzaklaştığı görülmektedir (Şekil 5c).
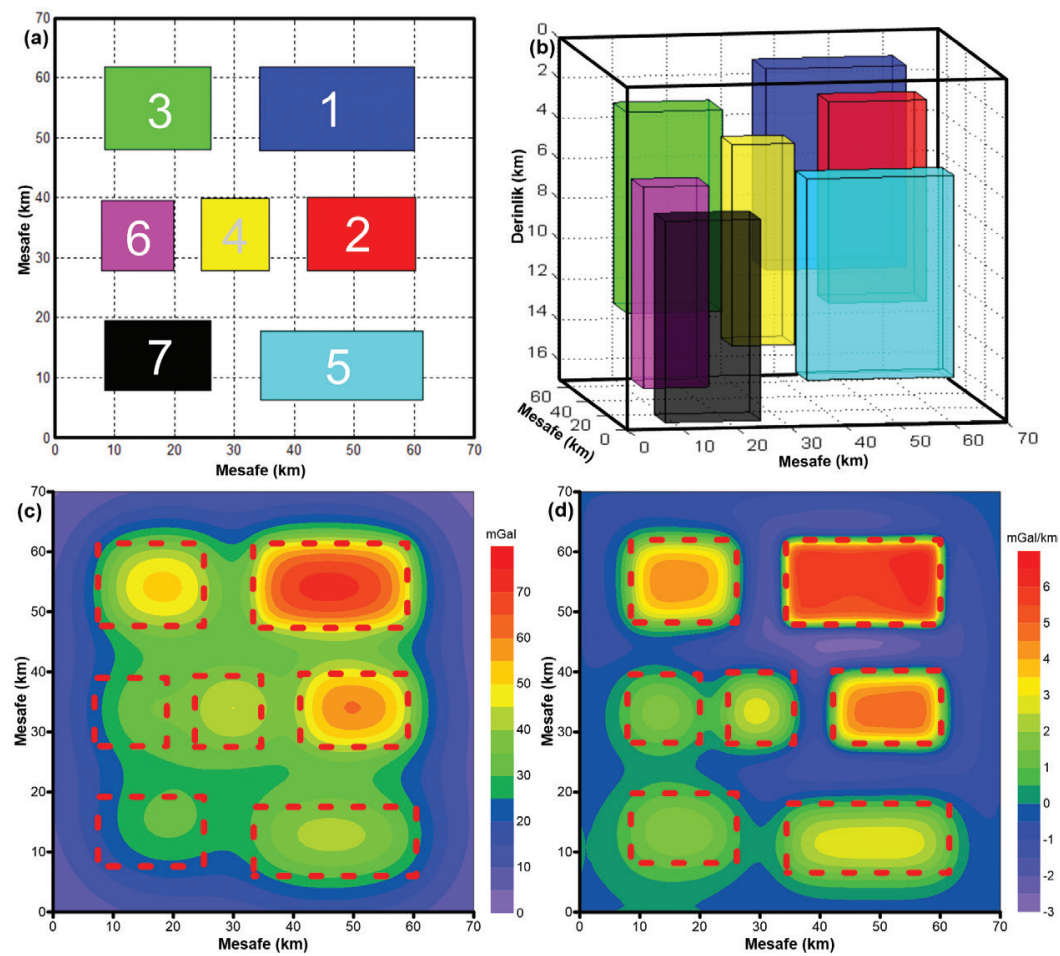

Şekil 4. a) Sonlu düşey prizmatik modeller, b) modellerin üç boyutlu görünümü, c) modellerin gravite anomali haritas1, d) gravite verilerinin birinci düşey türev haritası.

Figure 4. a) Finite vertical prismatic models, b) three-dimensional view of models, c) gravity anomaly map of the models, d) first vertical derivative map of the gravity data. 

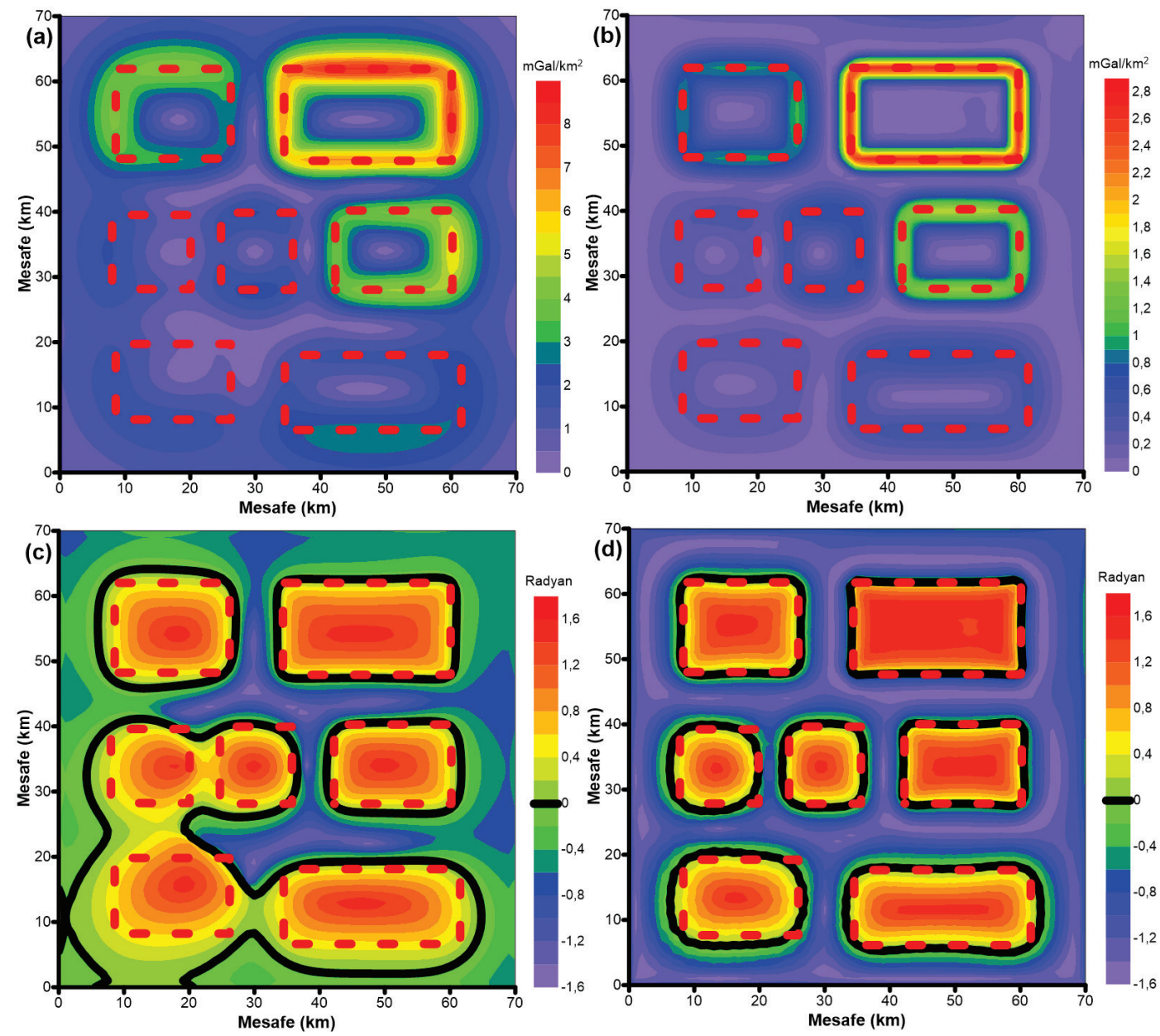

Şekil 5 .a) Gravite anomalisinin TYT haritası, b) gravitenin birinci düşey türev anomalisinin TYT haritası, c) gravite anomalisinin EA haritası, d) gravitenin birinci düşey türev anomalisinin EA haritası.

Figure 5. a) Horizontal gradient map of the gravity anomaly, b) horizontal gradient map of the first vertical derivative of the gravity anomaly, c) tilt angle map of the gravity anomaly, d) tilt angle map of the first vertical derivative of the gravity anomaly.

\section{Gravite Anomalilerinin Ayırımı ve Sınır Analizleri}

Bölgeye ait Bouguer gravite değerlerinin ve rejyonal gravite verilerinin birinci düşey türev değerlerinin bölgenin temel kaya topoğrafyası ve tektonik yapısıyla uyumlu olduğu görülmektedir (Şekil 6a ve 6d). Tabaka kalınlıklarındaki azalmaya bağlı olarak gravite değerleri Trodos Masifi üzerinde artmaktadır.
Çalışma alanının rejyonal gravite anomalisinin elde edilmesi için alçak geçişli süzgeç kullanılmıştır. Bouguer gravite, rejyonal gravite, yerel gravite ve birinci düşey türev haritaları sırasıyla Şekil $6 a, 6 b, 6 c$ ve $6 d$ 'de görülmektedir. 


\section{Elmas}
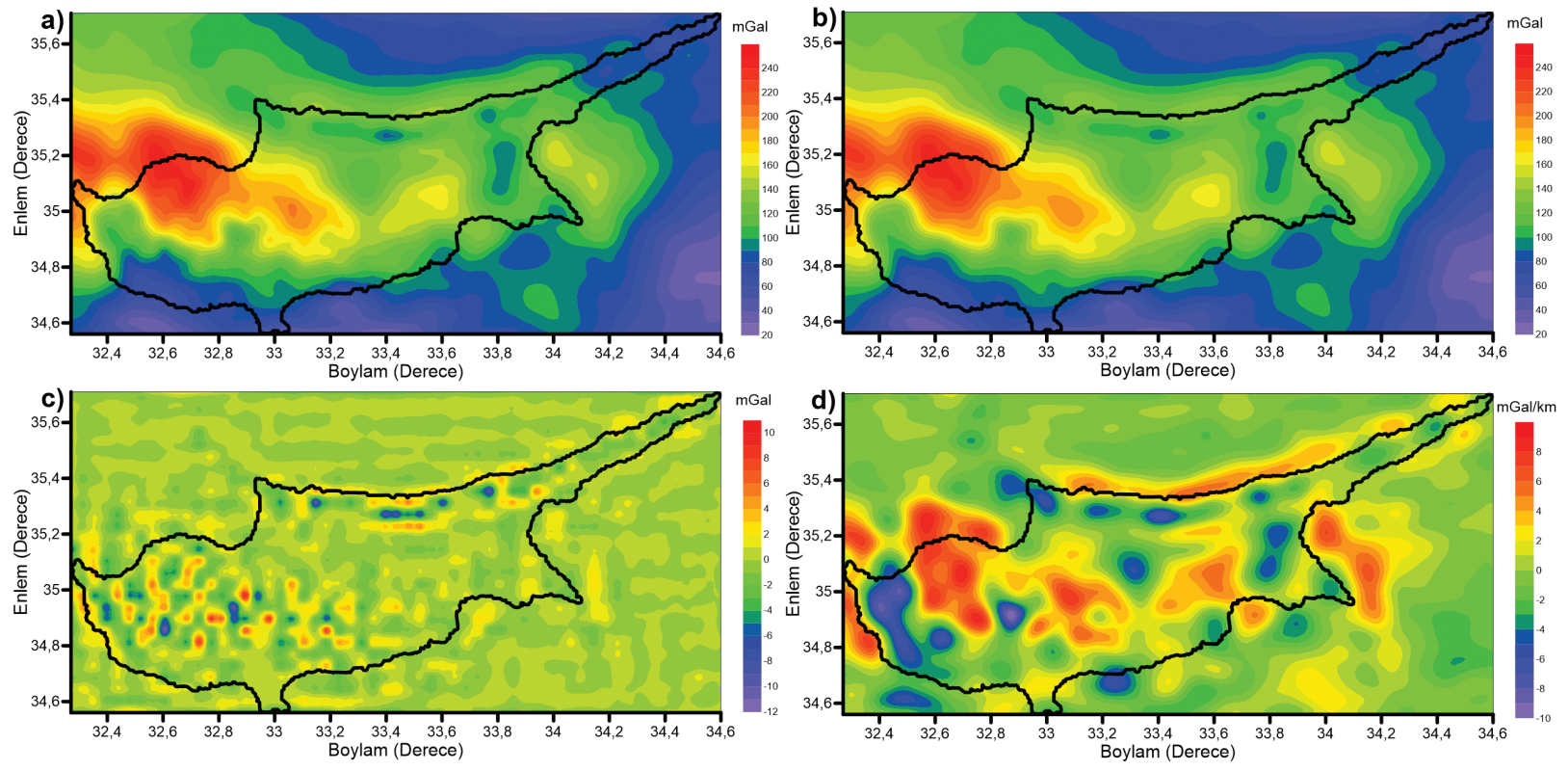

Şekil 6. a) Bouguer gravite haritas1, b) rejyonal gravite haritas1, c) yerel gravite haritası, d) rejyonal gravite verilerinin birinci düşey türev haritası.

Figure 6. a) Bouguer gravity map, b) regional gravity map, c) local gravity map, d) the first vertical derivative map of the regional gravity values.

Rejyonal gravite verilerinin birinci düşey türev değerlerinden hesaplanan TYT genliğinin maksimum değerleri ile EA genliğinin sıfır değerleri, çalışma alanındaki tektonik süreksizlikleri ve çizgisellikleri gösteren yapıları temsil etmektedir.

TYT'in maksimum genlik değerleri tektonik süreksizliklerin çeşitli doğrultularda uzanımlar sergilediklerini göstermektedir (Şekil 7a). Böylece, çalışma alanının bazı kısımlarındaki yeni fay türü yapılar ve yoğunluk fark1 sunan kütle sınırları, TYT genlik haritasında görülebilir (Şekil 7a). EA genlik haritasına bakıldığında ise, çizgisellik gösteren hem derin hem de sığ yap1 kenarları üstünde sıfır genlik değerleri görülmektedir (Şekil 7b). Bu genlik haritasından jeolojik süreksizliklerin değişik doğrultularda uzanım yaptıkları anlaşılmaktadır.

Altın ve gümüş gibi ekonomik değeri olan birçok maden yatağı ağırlıklı olarak tektonik süreksizlikler ile yakından ilișkili oldukları için (Ercan vd., 2014), Trodos Masifi'ndeki maden yataklarının yerlerini belirlemede tektonik yapıya işaret eden çizgiselliklerin önemi ortaya çıkmaktadır. Diğer taraftan, çizgisel yapıların bazıları aktif fayları, bazıları eski fayları ve bazıları da yoğunluk farkı sunan kütle sınırlarını temsil etmektedir. Önceden varlığ çalışma kapsamında belirlenen çizgisel yapılar Şekil 8'de görülmektedir. 

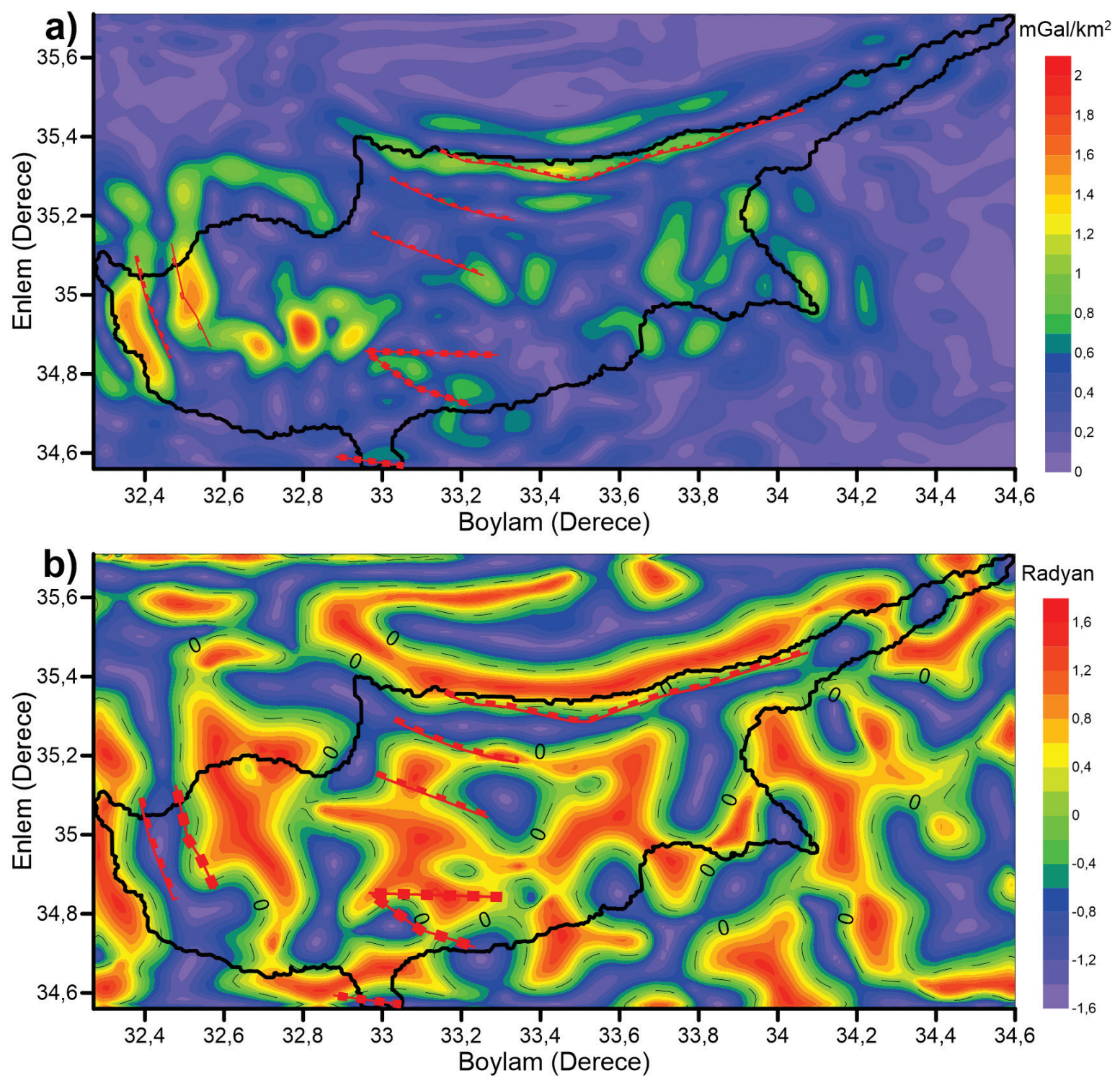

Şekil 7. Çalışma alanına ait rejyonal gravite verilerinin birinci düşey türev anomalisinin; a) TYT haritası, b) EA haritası (kırmızı çizgiler bilinen fayları göstermektedir).

Figure 7. a) Horizontal gradient magnitude of the first vertical derivative of the regional gravity anomaly, b) tilt angle map of the first vertical derivative of the regional gravity anomaly (red lines represent the known faults of the region). 
Elmas

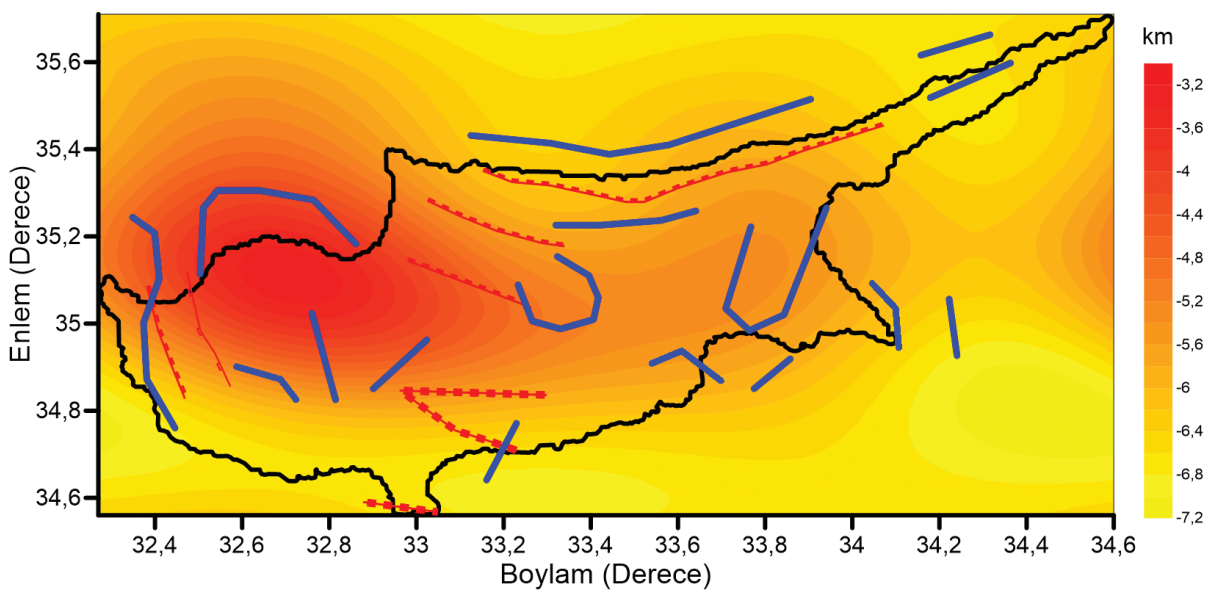

Şekil 8. Çalışma alanının temel kaya derinlikleri haritası (kırmızı çizgiler mevcut fayları ve mavi çizgiler de yeni bulunan çizgisel yapıları temsil etmektedir).

Figure 8. Depth to basement rock of the study area (red lines represent existing faults and blue lines represent newly found linear structures).

Çalışma alanına ait temel kaya topoğrafyası, rejyonal gravite verilerine Parker-Oldenburg algoritması uygulanarak belirlenmiştir (Şekil 8). Temel kaya topoğrafyasını hesaplamak için, genlik spektrumundan bulunan $5.89 \mathrm{~km}$ derinlik değeri, başlangıç derinlik değeri olarak kullanılmıştır. Metamorfik birim $\left(\sim 2.7 \mathrm{~g} / \mathrm{cm}^{3}\right)$ ile temel kaya derinliğine kadar olan Neojen sedimentleri $\left(\sim 2.4 \mathrm{~g} / \mathrm{cm}^{3}\right)$ arasındaki yoğunluk fark1 $0.3 \mathrm{~g} / \mathrm{cm}^{3}$ olarak belirlenmiştir. Yakınsama kriteri olarak $0.01 \mathrm{~km}$ seçilmiştir. Kesme dalga sayıları, genlik spektrumundan sirasıyla $0.87 \mathrm{~km}^{-1}$ ve $2.57 \mathrm{~km}^{-1}$ olarak belirlenmiştir. RMS hatası ve yineleme sayıs sirasiyla $0.003 \mathrm{~km}$ ve 6 'dir. Rejyonal gravite verileri ile hesaplanan temel kaya topoğrafyası arasında kuvvetli bir ilişki görülmektedir (Şekil $6 b$ ve 8). Antiklinalleri ve senklinalleri takip eden çizgisellikler, temel kaya topoğrafyasını kontrol etmektedir. Temel kaya topoğrafyasındaki alçalma ve yükselimlerdeki antiklinaller ve senklinaller arasındaki sınırların fay zonlarıyla ilişkili olmalarından dolayı (Oruç vd., 2013), bu gözlem beklentilerle uyumludur. Temel kaya topoğrafyasının en sığ yeri $3.2 \mathrm{~km}$ ile Trodos Masifi'nin kuzeybatı kısmında iken, en derin yeri ise $7.2 \mathrm{~km}$ ile diğer alanlarda olduğu açıkça görülmektedir. Temel kaya topoğrafyasındaki alçalma ve yükselimlerin faylarla kısmen uyumlu olduğu görülmektedir (Şekil 8).

\section{TARTIŞMALAR}

TYT ve EA sinır analiz teknikleri kullanılarak, çalışma alanında yeni fay türü yapılar ve çizgisellikler belirlenmiştir. $\mathrm{Bu}$ çalışmada kullanılan teknikler çalışma alanının rejyonal gravite verilerinin birinci düşey türev değerlerine ilk kez uygulanmıştır. Çalışma alanının bazı kısımlarında TYT haritasında maksimum genlik görülmezken, EA haritasında aynı kısımlarda sıfır genlik değerleri görülmüştür (Şekil 7a ve 7b). Gaudry (1862), Baroz (1979), McCallum ve Robertson (1995a, 1995b), Çuhadar vd. (1997), Hakyemez vd. (2002) ve Hakyemez (2004) Kıbrıs'da üç tektonik birimin sınırlarını belirlemişler, ancak bu çalışmada bulunan daha alt birimlere ait çizgiselliklere değinmemişlerdir. 
Yeni bulunan çizgisellikler Şekil 8'de açıkça görülmektedir. Ergon (1986), Kibris'in manyetik haritalarını veri-işlem yöntemleriyle analiz ederek bölgenin genel jeolojik yapısı ve bilinen cevher yataklarıyla olan ilişkilerini ele almıştır. Literatürde birçok araştırmacı Kıbrıs'ın Bouguer gravite anomalisini değişik yöntemlerle yorumlayarak çalışma alanına ait jeolojik birimleri belirlemeye çalışmışlardır (Moores ve Vine, 1971; Greenbaum, 1972; Bear, 1963; Gass ve Masson-Smith, 1963; Robertson,1975; Robertson ve Woodcock, 1979). Bu çalışmada ise, Parker-Oldenburg algoritması Kıbrıs'ın rejyonal gravite verilerine uygulanarak temel kaya topoğrafyası derinliğinin $3.2 \mathrm{~km}$ ile $7.2 \mathrm{~km}$ arasında değiştiği bulunmuştur. Khan vd. (1972) bu masifin $0.5 \mathrm{~km}$ kalınlığındaki yüzey tabakası altında iki kırılma yüzeyi saptamıştır ve ikinci katmanın kalınlığını $1.5 \mathrm{~km}$ ile $2.0 \mathrm{~km}$ arasında değiştiğini bulmuşlardır. Ancak bu araştırmacılar da bu çalışmada bulunan yeni fay türü yapılardan ve çizgiselliklerden bahsetmemişlerdir.

Literatürde mevcut olan, fay türü yapıları belirlemek için yapılmış gravite alanındaki çalıșmalarda TYT ve EA sınır analiz teknikleri genellikle Bouguer gravite verileriyle kullanılmıştır (Nabighian, 1972; Miller ve Singh, 1994; Lyngsie vd., 2006; Cooper ve Cowan, 2006). Bu çalışmada ise, bu teknikler rejyonal gravite verilerinin birinci düşey türev değerleriyle kullanılmıştır. Çalışmada, temel kaya topoğrafyasındaki antiklinal ve senklinallerle ilgili olarak yükselim ve alçalma bölgeleri de belirlenmiştir (Şekil 8).

Bölgenin çarpışma kuşağı içinde olması ve magmatik faaliyetin yaygın oluşu doğal olarak farklı gravite anomalileri üretmektedir. $\mathrm{Bu}$ kütlelerin yan kayaçlar ile dokanaklarını faylardan ayırt etmek için, bu çalışmanın sonuçlarından yararlanılarak daha farklı çalışmalar yapılmalıdır.
Ayrıca sınır analiz teknikleriyle belirlenen fay zonlarının paleotektonik mi, yoksa neotektonik aktif yapı mı olduğu ayrı bir araştırma konusudur.

\section{SONUÇLAR VE ÖNERILER}

$\mathrm{Bu}$ çalışmada, Kıbrıs Adası'nın çizgisellik haritası oluşturularak güncel tektonik yapısı verilmiştir. Kullanılan tekniklerin geçerliliğini ortaya koymak amaciyla farklı boyutlara ve derinliklere sahip olan dikdörtgen prizma şekilli yedi kuramsal model oluşturulmuştur. Daha sonra çalışma alanının temel kaya ondülasyonu rejyonal gravite verileri yardımıyla ortaya konulmuştur. İki farklı teknik kullanılarak belirlenen çizgiselliklerin yerleri, TYT haritasının maksimum genlik değerleri ve EA haritasının da sıfir konturları kullanılarak güncel tektonik yapı belirlenmiştir.

$\mathrm{Bu}$ çalışma ile, Kıbrıs Adası'nda daha önce gözlenmemiş çizgisellikler ortaya konulmuştur. Kıbris Adası'nın kuzey ve kuzeydoğu kesimlerinde, kuzeydoğu-güneybatı uzanımlı yeni çizgisellikler bulunmuştur. Adanın güneybatı kesiminde ise, çeşitli doğrultularda uzanım gösteren yeni çizgisellikler ve eski fayları kesen yeni çizgisellikler bulunmuştur. Çalışma sonucunda ortaya konulan tektonik yapının deprem üretebilecek kesimleri, daha sonra yapılacak olan çalışmalarla belirlenmelidir. Özellikle Litosfer-Astenosfer ve Moho sınırlarının modellenmesi gibi daha derin çalışmalarla, görüntülenen çizgiselliklerin ne derece deprem üretebilecekleri ortaya konulmalıdır. Bu çalışmadan elde edilen sonuçlar, gelecekte yapılacak olan kapsamlı jeofizik çalışmalarla desteklenirse, çalışma alanında henüz keşfedilmemiş maden yatakları ile deprem riskinin yüksek olduğu yerleri belirlemek daha kolay olacaktır. 
Elmas

\section{KATKI BELİRTME}

Yazar, bu çalışmadaki katkılarından dolayı, Kocaeli Üniversitesi'nden Prof. Dr. Bülent ORUÇ'a teşekkürlerini sunar.

\section{KAYNAKLAR}

Altınoğlu, F.F., Sarı, M., Aydın, A., 2015. Detection of Lineaments in Denizli Basin of Western Anatolia Region Using Bouguer Gravity Data. Pure and Applied Geophysics, 172, 415-425.

Ambraseys, N. N., Adams, R. D., 1993. Seismicity of the Cyprus region. Terra Nova, 5, 8-94.

Arısoy, M. Ö., Dikmen, Ü., 2011. Potensoft: MATLAB-based software for potential field data processing, modelling and mapping. Computer \& Geosciences, 37, 935-942.

Baroz, F., 1979. Étude géologique dans le Pentadaktylos et la Mésaoria (Chypre septentrionale). 2 volumes, $\mathrm{Ph}$. D. thesis, 365 p., University os Nancy, France.

Bear, L. M., 1963. The mineral resources and mining industry of Cyprus, Geology Survey Bulletin, 1, $184 \mathrm{p}$.

Bhattacharyya, B.K., 1967. Some general properties of potential fields in space and frequency domain: a review. Geoexploration 5 (3), 127-143.

Cooper, G. R. J., Cowan, D. R., 2006. Enhancing potential field data using filters based on the local phase. Computers and Geosciences, 32 (10), 1585-1591.

Çuhadar, Ö., Akça, N., Teymur, S., İlleez, H. İ., Alaygut, D., 1997. KKTC Beşparmak Dağları kuzeyindeki Miyosen yaşlı birimlerin stratigrafisi, petrografisi ve jeokimyasal değerlendirmesi. TPAO Rapor No. 3762, 36 s., Ankara.

Ercan, Ö. A., Şeren, A., Elmas, A., 2014. Gold and silver prospection using magnetic, radiometry and microgravity methods in the Kışladağ province of Western Turkey. Resource Geology, DOI: $10.1111 /$ rge. 12024 .
Ergon, M., 1986. Kıbrıs jeolojisi ve maden yatakları üzerine bazı jeofizik irdelemeler. Jeoloji Mühendisliği, 28, 35-42.

Evjen, H. M., 1936. The place of the vertical gradient in gravitational interpretations. Geophysics, 1, 127-136.

Gass, L. G., Masson-Smith, D., 1963. The geology and gravity anomalies of the Troodos Massif, Cyprus. Philosophical Transaction of the Royal Society, London, A255, 417-467.

Gaudry, A., 1862. Géologie de l'île de Chypre. Mém. Soc. Géol. France. Sér.2, 7(3), 106 p.

Gomez-Ortiz, D., Agarwal, B. N. P., 2005. 3DINVER.M: A MATLAB program to invert the gravity anomaly over a 3-D horizontal density interface by Parker-Oldenburg's algorithm. Computer Geosciences, 31, 513-520.

Greenbaum, B., 1972. Magmatic processes at oceanic ridges: Evidence from the Troodos Massif, Cyprus. Natural Philosophical Society, 238, 1821.

Gunn, P. J., 1975. Linear transformations of gravity and magnetic fields. Geophysical Prospecting, 23 (2), 300-312.

Hakyemez, H. Y., Turhan, N., Sönmez, İ., 2002. Kuzey Kıbris Türk Cumhuriyeti'nin jeolojisi. MTA Rapor No:10608, 69 s., Ankara.

Hakyemez, A., 2004. Kuzey Kibris OligosenPliyosen istiflerinin planktonik foraminifera biyostratigrafisi. Ankara Üniversitesi Fen Bilimleri Enstitüsü, Ankara, Doktora Tezi, $362 \mathrm{~s}$ (yayımlanmamış).

Kempler, D., Ben Avraham, Z., 1987. The tectonic evolution of the Cyprian Arc. Annual Tectonic, $1,58-71$.

Khan, M. A., Summers, C., Bamford, S. A. D., Chorston, N., Poster, K. vc Vine, F. J., 1972. A. reversed refraction line in the Troodos Massif, Cyprus. Nature Physical Science, 238, 134-136.

Lyngsie, S. B., Thybo, H., Rasmussen, T. M., 2006. Regional geological and tectonic structures of the North Sea area from potential field modelling. Tectonophysics, 413 (3-4), 147-170. 
McCallum, J. E., Robertson, A. H. F., 1995a. Sedimentology of two fan-delta systems in the Plio-Pleistocene of the Mesaoria Basin, Cyprus. Sedimentary Geology, 215-244.

McCallum, J. E., Robertson, A. H. F., 1995 b. Late Pliocene - early Pleistocene Athalassa Formation, north central Cyprus: carbonate sand bodies in a shallow seaway between two emerging landmasses. Terra Nova, 7, 265-277.

Miller, H. G., Singh, V., 1994. Potential field tilt -a new concept for location of potential field sources. Journal of Applied Geophysics, 32, 213-217.

Moores, E. M., Vine, F. J., 1971. The Troodos; Massif, Cyprus and other ophiolites as oceanic crust evaluation and implications. Philosophical Transaction of the Royal Society, 268, 443-468.

Nabighian, M. N., 1972. The Analytic Signal of two dimensional magnetic bodies with polygonal cross section: Its properties and use for automated anomaly interpretation. Geophysics, 37, 507-517.

Oldenburg, D. W., 1974. The inversion and interpretation of gravity anomalies. Geophysics, 39, 526-536.

Oruç, B., 2010. Edge detection and depth estimation using a tilt angle map from gravity gradient data of the Kozakl1-Central Anatolia Region, Turkey. Pure and Applied Geophysics, DOI: 10.1007/ s00024-010-0211-0.

Oruç, B., Keskinsezer, A., 2008. Structural setting of the northeastern Biga Peninsula (Turkey) from tilt derivatives of gravity gradient tensors and magnitude of horizontal gravity components. Pure Applied Geophysics, 165, 1913-1927.

Oruç, B. ve Selim, H., 2011. Interpretation of magnetic data in the Sinop area of Mid Black Sea, Turkey, using tilt derivative, Euler deconvolution, and discrete wavelet transform. Journal of Applied Geophysics 74, 194-204.

Oruç, B., Sertçelik, İ., Kafadar, Ö., Selim, H. H., 2013. Structural interpretation of the Erzurum Basin, Eastern Turkey, using curvature gravity gradient tensor and gravity inversion of basement relief. Journal of Applied Geophysics, 88,105-113.
Parker, R. L., 1973. The rapid calculation of potential anomalies. Geophysical Journal International, 31, 447-455.

Pavlis, N. K., Holmes, S. A., Kenyon, S. C., Factor. J. K., 2008. An earth gravitational model to degree 2160: EGM2008. EGU General Assembly 2008, Vienna, Austria, April 13-18, 2008. http:// earth-info.nga.mil/GandG/wgs84/gravitymod/ egm2008. (Erişim tarihi: 11 Şubat 2017).

Robertson, A. H. F., 1975. Cyprus umbers: basaltsediment, relationships on a Mesozoic ocean ridge. Journal of Geological Society, 131, 511531.

Robertson, A. H. F., 1977. Tertiary uplift history of the Troodos Massif, Cyprus. Geological Society of America Bulletin, 88, 1763-1772.

Robertson, A. H. F., Hudson, J. D., 1974. Pelagic sediments in the Cretaceous and Tertiary history of the Troodos Massif, Cyprus. In: Hsü, K. J., Jenkyns, C. H., (eds.), Pelagic sediments on the land and under the Sea. International Association of Sedimentologists, Special Publication, 1, 403436.

Robertson, A. H. F., Woodcock, N. H., 1979. Tectonic settings of the Troodos Massif in the east Mediterranean. Proceedings of International Ophiolite Symposium, Cyprus, 36-49.

Robertson, A. H. F., Woodcock, N. H., 1986. The role of the Kyrenia Range Lineament, Cyprus, in the geological evolution of the eastern Mediterranean area. Philosophical Transaction of the Royal Society, London, A 317, 141-177.

Robertson, A. H. F., Xenophontos, C., 1993. Development of concepts concerning the Troodos ophiolite and adjacent unit in Cyprus. In: Prichard, H.M., Alabaster, T., Harris, N. B. W., Neary, C. R., (eds.), Magmatic Processes and Plate Tectonics. Geological Society Special Publication, 76, 85-119.

Robertson, A. H. F., Kidd R. B., Ivanov A. F., Woodside J. M., Galindo-Zaldivar J., Nieto L., 1995. Eratosthenes Seamount, easternmost Mediterranean: Evidence of Plio-Quaternary 
Elmas

collisional-related processes in the easternmost Mediterranean. Terra Nova, 7, 254-264.

Sönmez, T., 2015. Doğu Marmara bölgesinin litosfer dinamiklerinin EGM08 gravite anomalileri, izostazik ve termomekanik analizlerle araştırılması. Yüksek Lisans Tezi, K.O.Ü., Fen Bilimleri Enstitüsü, Kocaeli.

Şengör, A. M. C., Y1lmaz, Y., 1981. Tethyan evolution ol Turkey : A plate tectonic approach. Tectonophysics, 75, $181-241$.
Vine, F. J., Moores, E. M., 1989. Paleomagnetic results from the Troodos igneous massif, Cyprus. Transactions American Geophysical Union, 50, 131.

Weiler, Y., 1965. The folded Kythrea Flysch in Cyprus. Ph. D. Thesis, The Hebrew University of Jerusalem, $71 \mathrm{p}$. 